\title{
Spatial distribution and activity of microbial extracellular enzymes in the water column of the Mariana Trench
}

\author{
HONGGE ZHANG ${ }^{1}$, JUNHAO DENG ${ }^{2}$, JUNWEI CAO ${ }^{1}$, \\ JIASONG FANG ${ }^{1}$ \\ ${ }^{1}$ Shanghai Engineering Research Center of Hadal Science and \\ Technology, College of Marine Sciences, Shanghai \\ Ocean University, Shanghai 201306, PR China. \\ jfang@hpu.edu \\ ${ }^{2}$ Faculty of Earth Sciences, China University of Geosciences, \\ Wuhan 430074, PR China
}

In marine environments, particulate organic carbon (POC) produced by primary productivity cannot be used by microorganisms directly, and only after being hydrolyzed by extracellular enzymes can it be utilized by microorganisms for respiration. Therefore, extracellular enzymes, as the initial drivers of high-molecular organic matter mineralization, play a crucial role in the rate and spatial distribution of marine carbon cycling, and are key participants in the marine carbon cycle. It has been shown that the greater the activity of microbial extracellular enzymes, the larger the amount of dissolved organic carbon (DOC) utilization will be, suggesting that DOC is being used to meet the energy requirements of deep-sea microbial communities. In this study, the spatial distribution and activity of three extracellular enzymes, aminopeptidase, $\alpha$-glucosidase, and $\beta$ glucosidase, in the water column of the Mariana Trench were determined by fluorescently labeled substrate method. The extracellular enzyme activity was significantly affected by pressure, as the degradation rate of the substrates by these extracellular enzymes decreases with increasing depth, and the surface seawater enzyme activity was significantly greater than that in the deep sea. Deep-sea pressure-producing microorganisms have high biological activity and can produce abundant extracellular enzymes to degrade different organic matter in the ocean. Our results suggest that microbial extracellular enzymes play a key role in oceanic carbon cycle.

Key words: Extracellular enzyme, high pressure, aminopeptidase, glucosidase 